\title{
Allergic aspergillosis: review of 32 cases
}

\author{
A. H. HEN DER S O N ${ }^{1}$ \\ From the United Bristol Hospitals, Bristol 2, and the Royal Devon and Exeter Hospital, Exeter
}

\begin{abstract}
The clinical, radiographic, and laboratory findings have been reviewed in a series of 22 patients with definite and 10 with probable allergic aspergillosis. Episodes of segmental shadowing occurred most frequently in the upper lobes and tended to recur in the same segment. Radiologically visible mucoid impaction of a large bronchus was demonstrated in eight cases, and saccular bronchiectasis in six cases, in the affected segments. Two patients have recovered, eight continued to experience episodic symptoms and shadows for up to 13 years, and 11 are on steroid therapy with relief of airways obstruction and prevention of further lung shadows. Four, together with five others who probably represent a late stage of the disease, have upper lobe contraction. One patient developed aspergillomas and one died with invasive aspergillosis. Sputum has remained positive in all except one patient. Precipitins were present in all cases. They varied widely in strength and appeared to be more closely related to the amount of antigenic exposure than to the severity of the allergic manifestations. Allergy to Aspergillus fumigatus probably plays a dominant role in the symptomatology of those with asthma of late onset; evidence of underlying atopic diathesis and of increased spore exposure could usually be adduced in these patients. A quantitative interaction of atopic diathesis and contact with a growing source of fungal antigens will result in a locally florid bronchial reaction, with plugging and subsequent dilatation. The peripheral shadows are consistent with areas of collapse distal to bronchial occlusion. The frequency and distribution of mucoid impaction found in this series suggest that allergic aspergillosis may be a major cause of this uncommon syndrome, which could represent an exaggerated form of bronchial plugging.
\end{abstract}

It has become increasingly apparent in recent years that allergic aspergillosis is one of the commoner causes of pulmonary eosinophilia and that it may cause permanent lung damage. An association between asthma and aspergillosis was noted in 1925 by van Leeuwen, Bien, Kremer, and Varekamp, and this has been confirmed by the finding of Aspergillus species more commonly in the sputum of patients with asthma than with other lung diseases (Pepys, Riddell, Citron, Clayton, and Short, 1959; Chakravarty, 1964). Conant, Smith, Baker, Callaway, and Martin (1944) described the occurrence of transient lung shadowing with sensitization to Aspergillus species, and in 1952 Hinson, Moon, and Plummer reported three patients who had experienced recurrent attacks of wheezy bronchitis with fever, lung shadows, eosinophilia, and bronchial phugging by viscid secretions containing scanty Aspergillus fumigatus hyphae. Immediate skin and bronchial hypersensitivity and precipitating serum antibodies to $\boldsymbol{A}$. fumigatus extracts were demon-

1Present address: Peter Bent Brigham Hospital, Boston, Mass., U.S.A. strated by Pepys et al. (1959) and by Longbottom and Pepys (1964) in groups of similar patients. Campbell and Clayton (1964) reported positive skin tests in $99 \%$ and precipitins in $69 \%$ of patients with allergic aspergillosis, and Pepys (1966a) has emphasized the possible role of precipitins in its pathogenesis.

Allergic aspergillosis is not an uncommon condition, but there have been few comprehensive clinical accounts (Hinson et al., 1952 ; Citron and Pepys, 1958 ; Hinson, 1958 ; Plummer, 1958 ; Golberg, 1962 ; Ellis, 1965 ; Scadding, 1967) or studies of its natural history. A series of 22 typical patients, together with 10 others who showed some features of allergic aspergillosis, is therefore here reported to illustrate the clinical spectrum of the disease.

\section{SUBJECTS}

Five patients with allergic aspergillosis were seen in Bristol, forming part of a survey of 107 consecutive patients with chronic lung disease seen in one year 
(Henderson, English, and Vecht, 1968), and 17 were seen in Exeter during a period of eight months. Two of the Bristol and seven of the Exeter patients were newly diagnosed during the periods of study. The 10 other patients with probable allergic aspergillosis were drawn from the same sources.

\section{DIAGNOSTIC CRITERIA}

ALLERGIC ASPERGILLOSIS The diagnosis of allergic aspergillosis was regarded as established only if a positive skin test was associated with episodic airways obstruction (forced expiratory volume in one second less than $70 \%$ of vital capacity), transient lung shadows in different sites, eosinophilia (shown by an absolute blood eosinophil count of more than $500 / \mathrm{cu}$. mm. at any time), and sputum containing 'abundant fungus' (see Methods).

PROBABLE ALLERgIC ASPERgILlosis All patients in this group had airways obstruction, a positive skin test, one or more but not all of the other listed criteria, and serum precipitins.

ASPERgILlOMA This diagnosis was established on the typical radiological appearance (Golberg, 1962), with supporting evidence that the mass was due to Aspergillus species.

INVASIVE ASPERgILlosis This diagnosis was established on the histological features with cultural identification of the fungus.

\section{METHODS}

Sputum and precipitins were investigated by a medical mycologist (Mary P. English) using the methods described by English and Henderson (1967).

SPUTUM Three specimens from each patient were examined. In an attempt to discount atmospheric contamination, sputum was regarded as positive only if 'abundant fungus' was present, defined thus: $A$. fumigatus cultured from more than one specimen or growing more than two colonies from one specimen. The finding of abundant, but not of scanty, fungus in the sputum has been shown to be associated with the presence of precipitins (English and Henderson, 1967).

PRECIPITINS Positive sera were arbitrarily graded into groups $A$ to $D$, in descending order of strength, by 'reactivity', the maximum number of precipitation lines produced with any of the antigenic extracts tried, and 'range', the number of antigenic extracts with which a reaction occurred out of the number tried (Table I).

SKIN TESTS Intradermal tests using control and $A$. fumigatus antigens (Bencard) were performed. To
T A B L E I

CLASSIFICATION OF PRECIPITINS

\begin{tabular}{|c|c|c|}
\hline Group & $\begin{array}{c}\text { Reactivity } \\
\text { (max. no. of lines) }\end{array}$ & $\begin{array}{c}\text { Range } \\
\text { (no. of antigens) }\end{array}$ \\
\hline $\begin{array}{l}\text { A } \\
\text { B } \\
\text { C } \\
\text { D }\end{array}$ & $\begin{array}{l}3-7 \\
3-4 \\
1-2 \\
1-2\end{array}$ & $\begin{aligned} & \text { All of } 6 \text { or more } \\
> & 75 \% \text { of } 6 \text { or more } \\
>75 \% \text { of } 7 \text { or more } & 75 \% \text { of } 7 \text { or more }\end{aligned}$ \\
\hline
\end{tabular}

avoid doubtful results, a positive result was recordedu only when the test produced an immediate wheads greater than $12 \mathrm{~mm}$. in diameter with erythemgr $(++++$ by the manufacturers' definition).

\section{RESULTS}

The clinical, radiological, and laboratory finding $\mathbb{\mathbb { P }}$ in patients with allergic aspergillosis are shown i Table II and those in patients with probablo allergic aspergillosis in Table III.

CLINICAL ANALYSIS The series contained $1 \mathbb{\$}^{\circ}$ female and seven male patients with allergie aspergillosis, and seven female and three male patients with probable allergic aspergillosis, thus showing a significant sex difference with a ratio of two females to one male $\left(\chi^{2}-\mathbf{P}<0.05\right.$ for the total series, assuming equal sex ratio in com munity). Two patients were siblings (cases 5 and 6).

Eleven patients (cases 1 to 11) with allergies aspergillosis gave a history of lifelong asthma The other 11 (cases 12 to 22) first experienced respiratory symptoms later, at ages ranging from 11 to 49 years (average 33 years).

Of the patients with late onset asthma, Table IV shows that eight (cases $12,13,15,18$ to 2 28 also showed other evidence of atopic diathesis $\$$ in addition, four (cases 12, 13, 17, 20) had had attacks of pneumonia or pertussis in infancy only two (cases 14 and 16) gave no history of an of these features.

Pulmonary shadows were first demonstrated $a \mathscr{P}$ ages ranging from 11 to 55 years. The average age of onset in patients with lifelong asthma wał 24 years $( \pm 4.2$ standard error of means) which is significantly different from the average age of 39 years $( \pm 3.7)$ in patients with late onset asthm (Student's $t$ test $\mathrm{P}<0.025$ ). The interval betweerf the onset of symptoms and the appearance of shadows was at least 10 years in all of the forme group but averaged less than one year in a except three patients (cases $13,17,19$ ) in the latteg group, one of whom (case 17) had not previousl罍 attended hospital. 
T A B L E I I

PATIENTS WITH ALLERGIC ASPERGILLOSIS: CLINICAL, RADIOGRAPHIC, AND LABORATORY DATA

\begin{tabular}{|c|c|c|c|c|c|c|c|c|c|c|c|c|c|c|}
\hline \multirow[b]{2}{*}{$\begin{array}{l}\text { Case } \\
\text { No. }\end{array}$} & \multirow[b]{2}{*}{ Age } & \multirow[b]{2}{*}{ Sex } & \multicolumn{3}{|c|}{ Respiratory Symptoms } & \multicolumn{5}{|c|}{ Lung Shadows } & \multirow[b]{2}{*}{$\begin{array}{c}\text { Bronchogram } \\
\text { (year) }\end{array}$} & \multirow[b]{2}{*}{$\begin{array}{l}\text { Pre- } \\
\text { cipitins } \\
\text { (group) }\end{array}$} & \multirow[b]{2}{*}{$\begin{array}{c}\text { Steroid } \\
\text { Treat- } \\
\text { ment } \\
\text { (years) }\end{array}$} & \multirow[b]{2}{*}{$\begin{array}{l}\text { Expo- } \\
\text { sure }\end{array}$} \\
\hline & & & $\begin{array}{l}\text { Age } \\
\text { of } \\
\text { Onset }\end{array}$ & $\begin{array}{l}\text { Years } \\
\text { now } \\
\text { Symp- } \\
\text { tom-free }\end{array}$ & $\begin{array}{c}\text { Haemo- } \\
\text { ptysis }\end{array}$ & $\begin{array}{l}\text { Age } \\
\text { of } \\
\text { Onset }\end{array}$ & $\begin{array}{l}\text { Duration } \\
\text { of Inter- } \\
\text { mittent } \\
\text { Shadows } \\
\text { (years) }\end{array}$ & $\begin{array}{l}\text { Years } \\
\text { since } \\
\text { Last } \\
\text { Shadow }\end{array}$ & $\begin{array}{c}\text { Mucoid } \\
\text { Impac- } \\
\text { tion }\end{array}$ & $\begin{array}{l}\text { Chronic } \\
\text { Upper } \\
\text { Lobe } \\
\text { Contrac- } \\
\text { tion }\end{array}$ & & & & \\
\hline $\begin{array}{l}1 \\
2\end{array}$ & $\begin{array}{l}20 \\
21\end{array}$ & $\underset{\mathbf{F}}{\mathbf{M}}$ & $\begin{array}{l}\text { c. } 2 \\
\text { c. } 2\end{array}$ & $\begin{array}{l}\mathbf{0} \\
\mathbf{0}\end{array}$ & + & $\begin{array}{l}20 \\
18\end{array}$ & $\begin{array}{l}1 \\
3\end{array}$ & $\begin{array}{l}\mathbf{0} \\
\mathbf{0}\end{array}$ & & & $\begin{array}{c}\text { Bronchiectasis } \\
1967\end{array}$ & $\begin{array}{l}\mathbf{D} \\
\mathbf{A}\end{array}$ & & \\
\hline $\begin{array}{l}3 \\
4 \\
5\end{array}$ & $\begin{array}{l}23 \\
24 \\
29\end{array}$ & $\begin{array}{l}\mathbf{F} \\
\mathbf{F} \\
\mathbf{M}\end{array}$ & $\begin{array}{l}\text { c. } 2 \\
\text { c. } 2 \\
\text { c. } 2\end{array}$ & $\begin{array}{l}\mathbf{0} \\
\mathbf{0} \\
\mathbf{0}\end{array}$ & $\stackrel{+}{+}$ & $\begin{array}{l}22 \\
17 \\
15\end{array}$ & $\begin{array}{l}1 \\
4 \\
?\end{array}$ & $\begin{array}{l}\mathbf{0} \\
\mathbf{3} \\
?\end{array}$ & + & & $\begin{array}{l}\text { Bronchiectasis } \\
1967\end{array}$ & $\begin{array}{l}\mathbf{A} \\
\mathbf{D} \\
\mathbf{A}\end{array}$ & 5 & \\
\hline 6 & 30 & $\mathbf{F}$ & c. 2 & 0 & + & 16 & 13 & 1 & + & & $\begin{array}{l}\text { Bronchiectasis } \\
1964\end{array}$ & D & 3 & \\
\hline 7 & 30 & $\mathbf{F}$ & c. 2 & 0 & & 13 & 10 & 7 & & + & $\begin{array}{l}\text { Bronchiectasis } \\
1952\end{array}$ & $\mathbf{A}$ & 5 & $\begin{array}{l}\text { Bird } \\
\text { seed }\end{array}$ \\
\hline $\begin{array}{r}8 \\
9 \\
10 \\
11 \\
12\end{array}$ & $\begin{array}{l}37 \\
40 \\
52 \\
54 \\
20\end{array}$ & $\begin{array}{l}\mathbf{F} \\
\mathbf{M} \\
\mathbf{F} \\
\mathbf{F} \\
\mathbf{F}\end{array}$ & $\begin{array}{l}\text { c. } 2 \\
\text { c. } 2 \\
\text { c. } 2 \\
\text { c. } 2 \\
11\end{array}$ & $\begin{array}{l}\mathbf{0} \\
\mathbf{0} \\
\mathbf{0} \\
\mathbf{0} \\
\mathbf{0}\end{array}$ & + & $\begin{array}{l}28 \\
16 \\
49 \\
54 \\
11\end{array}$ & $\begin{array}{l}9 \\
7 \\
3 \\
1 \\
8\end{array}$ & $\begin{array}{l}0 \\
7 \\
0 \\
0 \\
1\end{array}$ & + & + & $\begin{array}{l}\text { Normal } 1959 \\
\text { Bronchiectasis } \\
1967\end{array}$ & $\begin{array}{l}\mathbf{A} \\
\mathbf{C} \\
\mathbf{A} \\
\mathbf{A} \\
\mathbf{A}\end{array}$ & 7 & \\
\hline $\begin{array}{l}13 \\
14 \\
15 \\
16 \\
17 \\
18 \\
19 \\
20 \\
21 \\
22\end{array}$ & $\begin{array}{l}57 \\
33 \\
34 \\
37 \\
52 \\
36 \\
55 \\
46 \\
51 \\
64\end{array}$ & $\begin{array}{l}\mathbf{F} \\
\mathbf{M} \\
\mathbf{M} \\
\mathbf{M} \\
\mathbf{F} \\
\mathbf{F} \\
\mathbf{F} \\
\mathbf{F} \\
\mathbf{F} \\
\mathbf{M}\end{array}$ & $\begin{array}{l}15 \\
31 \\
31 \\
31 \\
33 \\
35 \\
35 \\
44 \\
46 \\
49\end{array}$ & $\begin{array}{l}0 \\
0 \\
0 \\
0 \\
0 \\
0 \\
0 \\
0 \\
0 \\
2 \\
6\end{array}$ & $\begin{array}{l}+ \\
+\end{array}$ & $\begin{array}{l}47 \\
31 \\
32 \\
34 \\
45 \\
35 \\
55 \\
44 \\
46 \\
49\end{array}$ & $\begin{array}{l}9 \\
1 \\
1 \\
3 \\
7 \\
1 \\
1 \\
2 \\
3 \\
9\end{array}$ & $\begin{array}{l}1 \\
1 \\
2 \\
0 \\
0 \\
0 \\
0 \\
0 \\
2 \\
6\end{array}$ & $\begin{array}{l}+ \\
+ \\
+ \\
+\end{array}$ & + & $\begin{array}{l}\text { Normal } 1966 \\
\text { Normal } 1964 \\
\begin{array}{l}\text { Bronchiectasis } \\
1962\end{array}\end{array}$ & $\begin{array}{l}\mathbf{A} \\
\mathbf{D} \\
\mathbf{D} \\
\mathbf{A} \\
\mathbf{A} \\
\mathbf{D} \\
\mathbf{A} \\
\mathbf{A} \\
\mathbf{C} \\
\mathbf{D}\end{array}$ & $\begin{array}{l}8 \\
2\end{array}$ & $\begin{array}{l}\text { Grain } \\
\text { Farmer } \\
\text { Farmer } \\
\text { Farm } \\
\text { Farm } \\
\text { Farmer }\end{array}$ \\
\hline
\end{tabular}

All 32 patients with definite or probable allergic aspergillosis had airways obstruction, but not all gave a history of asthmatic attacks. Eighteen also had intermittent productive cough. Eleven (cases 2,4 to $6,10,15,16,20,22,26,28$ ) had experienced scanty haemoptysis. Only four (cases 7 , $10,15,22)$ gave a clear history of expectorating plugs in the sputum. Eleven (cases 1, 2, 9, 10, 12, 14,16 to $18,21,22$ ) were pyrexial with one or more episodes of pulmonary shadowing. New shadows were generally associated with an exacerbation of dyspnoea, and one patient had pleuritic pain ; however, in some cases with current asthma (cases 14 and 18) there was no associated change in symptoms. The onset of the disease in previously healthy adults was characterized by a febrile illness with wheezy dyspnoea and a productive cough (cases 14 to 22).

ENVIRONMENTAL FACTORS Seven patients with definite and two with probable allergic aspergillosis gave a history suggesting contact with heavy doses of $\boldsymbol{A}$. fumigatus spores. Five patients (cases 15 to $17,19,22)$ lived or worked on farms. One patient (case 7) kept pet birds, and two (cases 14 and 26) came into contact with straw or grain at work, $\boldsymbol{A}$. fumigatus being cultured from the suspected source in each of these last three cases.
One patient (case 32) developed constant respiratory symptoms and lung shadowing after her bed had been moved close to the debris from birds' nests. One of the farmers (case 15) noted that his symptoms were exacerbated on several occasions after dealing with stored hay. One of the patients who worked with grain (case 14) developed symptoms for the first time within one month of starting this work. Increased environmental risk was present in six cases with late onset asthma and in only one with asthma since childhood (Table III).

RADIOGRAPHIC ANALYSIS The distribution of the radiographic lesions is shown in Table $\mathrm{V}$.

The peripheral lesions consisted of segmental shadowing of variable extent with some deflation (Figs 1 and 2). They occurred significantly more commonly in the upper lobes (excluding the lingula) than in all the other lobes together (including the lingula) and were seen especially in the apical segments. The same segment was affected more than once in 17 patients. The recorded duration of the shadows ranged from one week to six months.

Mucoid impaction of large bronchi was seen in eight patients (cases $5,6,8,12,16,17,19,20$ ) (Figs 2, 3, and 4). These shadows were continuous 


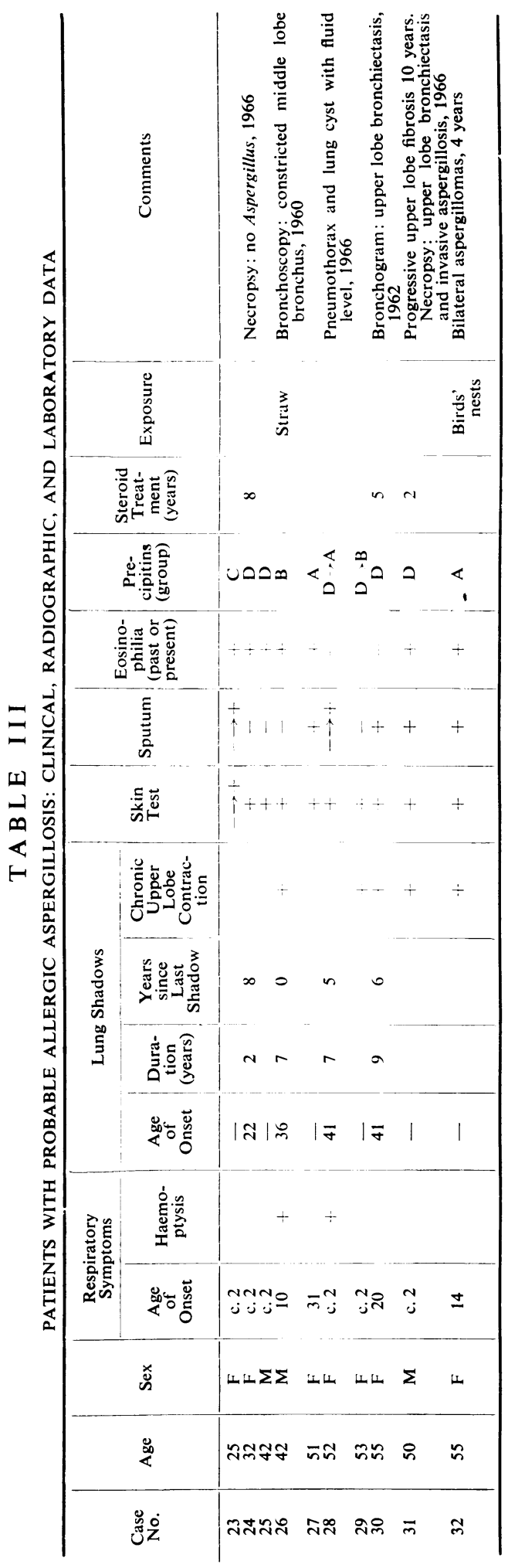

T A B L E IV

PATIENTS WITH ALLERGIC ASPERGILLOSIS AND LAT ONSET RESPIRATORY SYMPTOMS: POSSIBLE CONTR BUTORY FACTORS

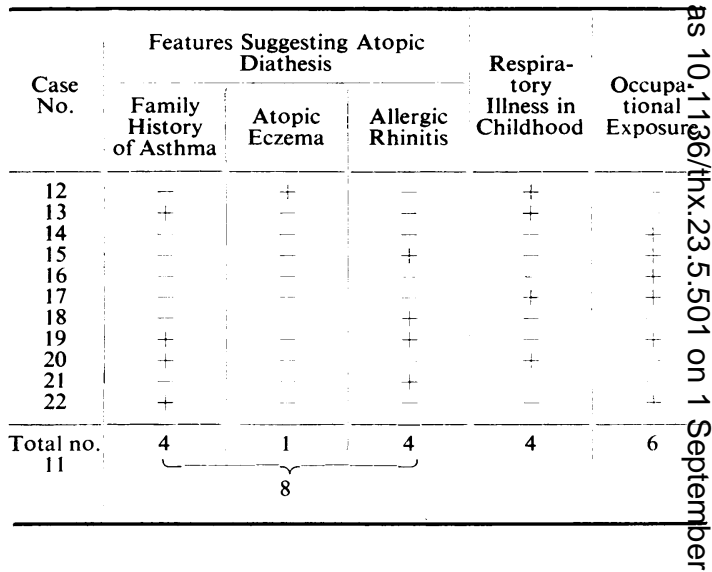

with the hilum proximally and blunt-ended dif tally. Some incorporated a bronchial bifurcatio Their calibre varied widely from patient to patient. Some dilated bronchi appeared opaque one time and thick-walled with radiolucent cowtents at another. All except one of the affected bronchi supplied the upper lobes, a significa ent $^{2}$ association. The segment supplied was in all cases the site of a previous peripheral opacity. Ta lesions persisted for several months and in two patients recurred.

Bronchograms, performed at some time nine patients (Table II), showed saccular bronchi ectasis involving mainly upper lobe segmental and smaller bronchi in six patients (cases 2, 5, 6, $\frac{8}{3}$, 12,16) (Figs 2 and 4) and normal appearances three (cases $7,14,22$ ). In some segments whig had been the sites of peripheral shadowing,

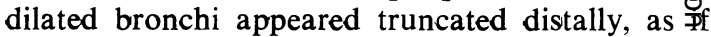
still occluded. Saccular bronchiectasis w demonstrated in all cases with mucoid impactio where bronchography was subsequently pes formed.

Nine patients (cases 7, 9,10,19,26, 29 to 3 R (Fig. 5), probably all with long-standing allergid aspergillosis, showed some degree of chronic coktraction of the upper lobes with linear opacitien.

COURSE OF THE DISEASE Two patients (cases 21 and 22) have been free of respiratory symptongs and shadows for two and six years respectivel Eleven patients (cases 1, 4, 6, 7, 9, 13 to 16,1 \% 19) are on steroid treatment for relief of airwa obstruction, with prevention of new lung shadows when given in adequate doses. One patient (ca\&e 


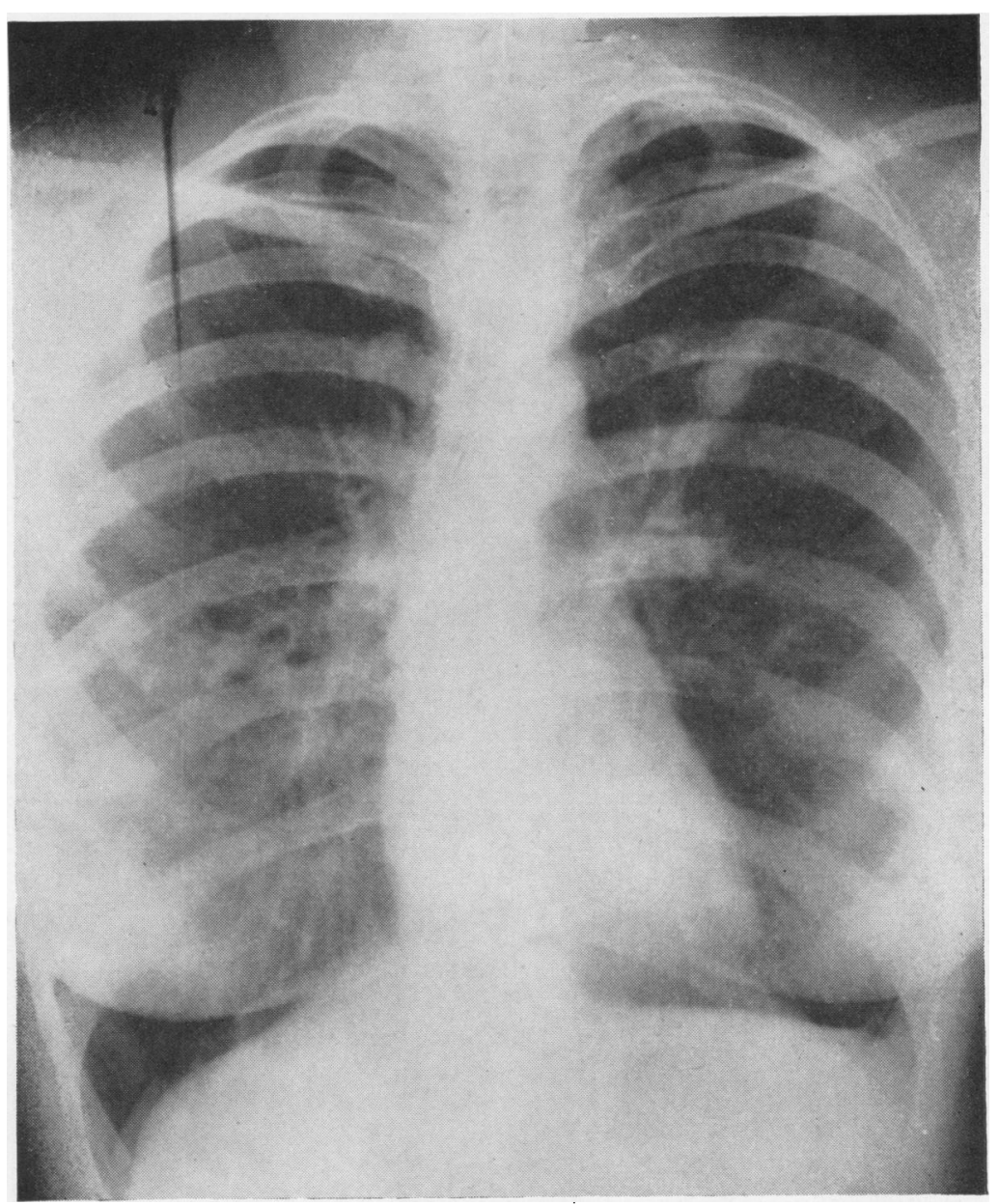

FIG. 1. Case 3. Chest radiograph showing bilateral shadows.

T A B L E V

DISTRIBUTION OF LUNG SHADOWS IN PATIENTS WITH ALLERGIC ASPERGILLOSIS

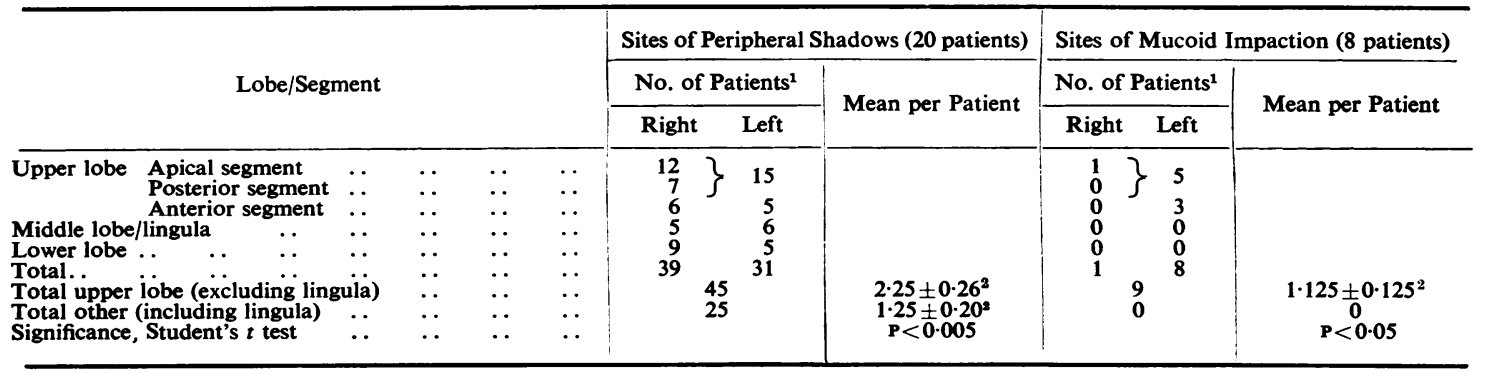

\footnotetext{
${ }^{1}$ In 17 patients peripheral shadows also recurred in the same segment, 10 in the upper lobes. In 2 patients mucoid impaction also 1 recurred in the same segment.
}

${ }^{2}$ Standard error of means. 


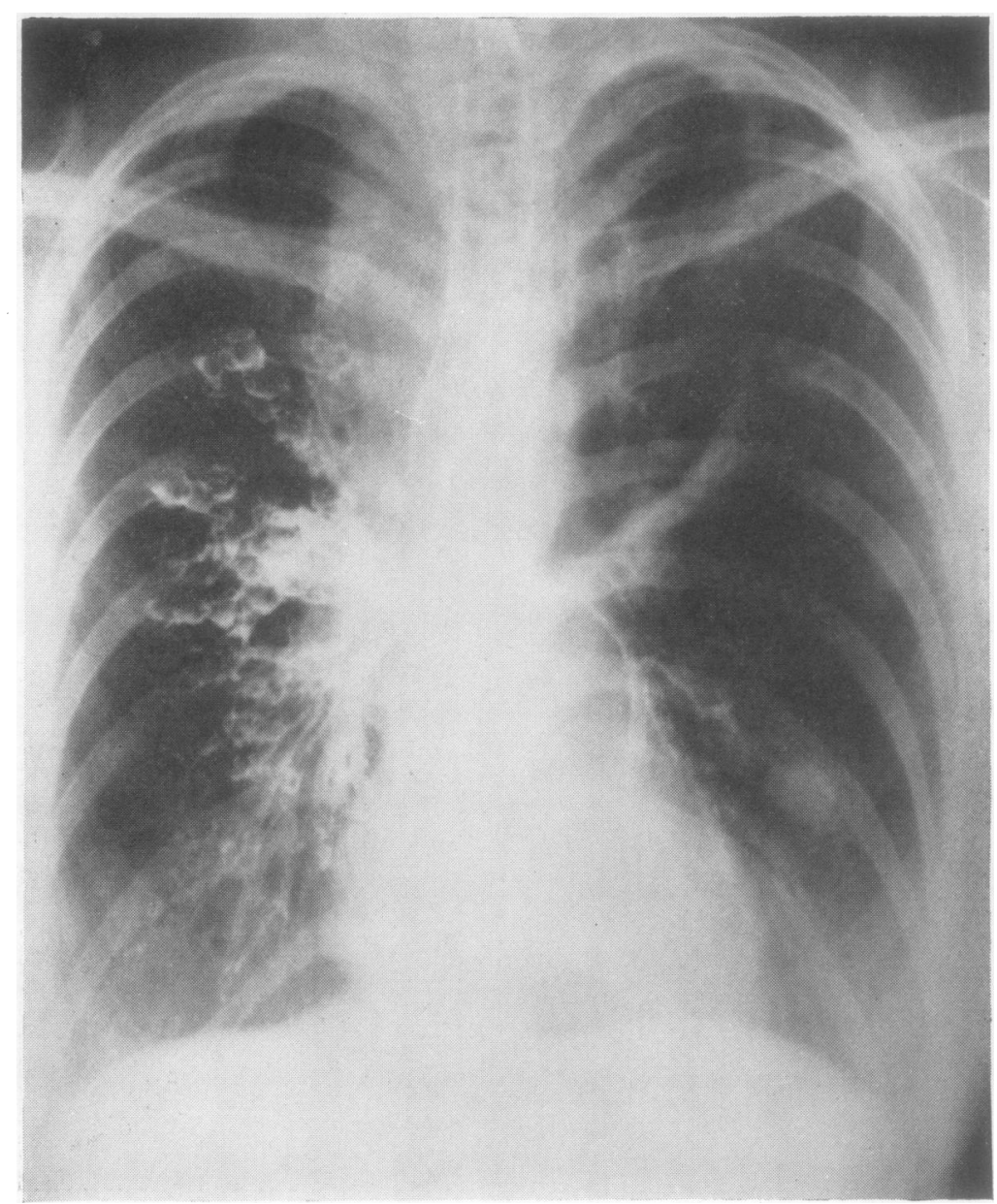

FIG. 2. Case 12. Chest radiograph with bronchogram showing right apical collapse, saccular bronchiectasis, and mucoid impaction of left apical bronchus.

5), who was first shown to have lung shadows 14 years ago, has experienced only minor episodes of asthma or infective bronchitis; no radiographs were taken in the intervening years, but there is now mucoid impaction without peripheral shadows (Fig. 3). The remaining eight patients are still subject to respiratory symptoms and recurrent shadows. The maximum recorded duration of intermittent shadowing in any patient was 13 years (case 6).

Of the nine patients with chronic upper lobe contraction and fixed airways obstruction, six were over the age of 50 years. Four had definite allergic aspergillosis, of long standing in two patients (cases 7 and 9), and with a history sug- gestive of long-standing disease in the other two (cases 10 and 19). The five with probable allergffes aspergillosis all showed evidence of chronis fungal infection and hypersensitivity, with pos tive skin test and precipitins; three (cases 30 to 32) had positive sputum, and three (cases $26,3 \overline{4}$, 32) had had eosinophilia; lung shadows had beem shown in two patients (cases 26 and 30), anf upper lobe saccular bronchiectasis was demoñstrated by bronchography in one (case 30) and necropsy in another (case 31). One (case 3\%) showed radiographic evidence of developing upper lobe fibrosis and then bilateral asperge lomas. Four patients (cases 7, 9, 30, 31) had been on steroids; one of these (case 31) (Fig. 5) wg 
tion of respiratory symptoms. They also had an earlier onset, longer duration, and, during the last five years, a higher frequency of demonstrated shadows, and a more recently continuing history of respiratory symptoms and pulmonary shadows, than the patients with weak precipitins, although these differences were not in this series separately of statistical significance. Conversely, the two patients (cases 21 and 22) who had been free of symptoms and shadows for some years both had weak precipitins.

Allergic episodes with lung shadows occurred both in patients with weak precipitins (cases 1 and 18) and in patients with precipitins as strong as are typically found in patients with aspergil-

FIG. 3. Case 5. Left upper and middle zones of chest tomogram showing mucoid impaction.

found at necropsy to have invasive aspergillosis with giant-cell granulomata containing hyphae of A. fumigatus.

PRECIPITINS Serum precipitins were present in all patients with allergic aspergillosis and ranged from strong (group A) to weak (group D). Table VI compares the clinical features, in patients not on steroids, of those with strong precipitins and those with weak precipitins. The possibility that steroids depress precipitins is supported by the finding that all patients with radiographic evidence of mucoid impaction had strong precipitins except the one on steroid therapy (case 6), and by the fact that strong precipitins were found in only two patients on steroid therapy (cases 7 and 13), although no statistically significant conclusions could be drawn from this small series.

Strong precipitins were associated with every feature indicating heavier or more prolonged fungal growth. Patients with strong precipitins had a significantly earlier onset and longer dura-

FIG. 4. Case 6. Left bronchogram showing characteristic

saccular bronchiectasis and site of previous mucoid
impaction.

saccular bronchiectasis and site of previous mucoid
impaction.

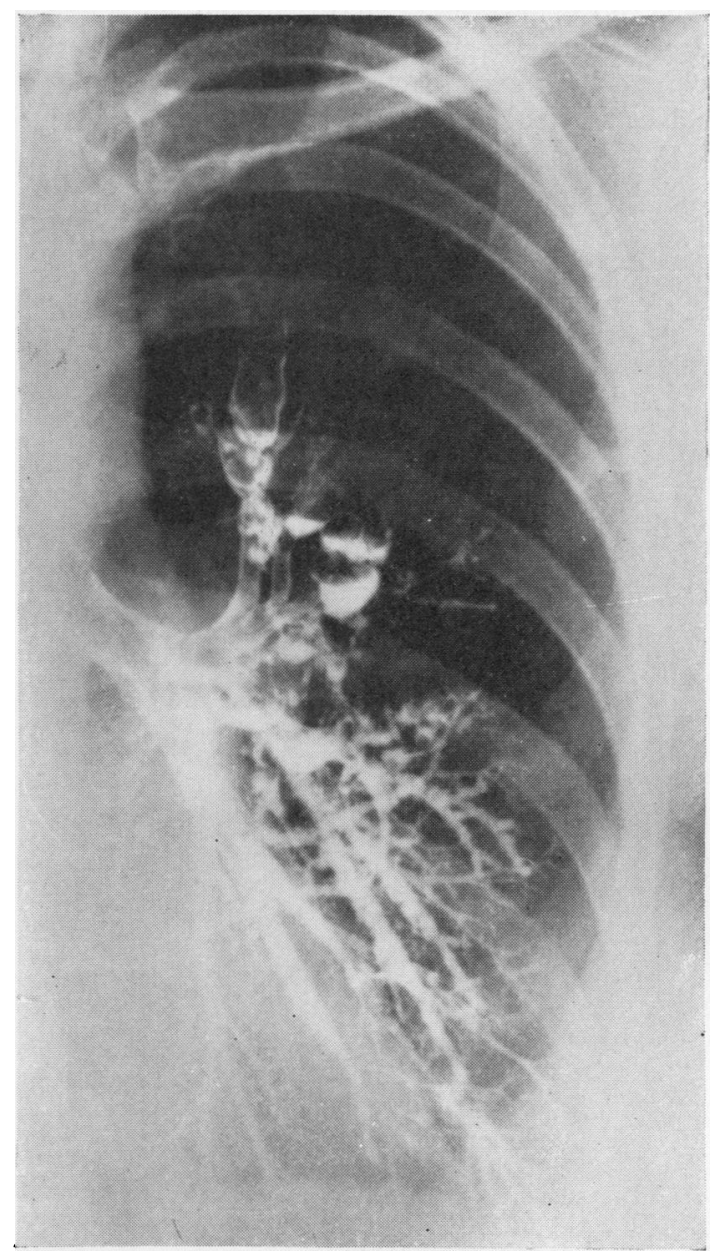


T A B L E V I

ALLERGIC ASPERGILLOSIS: COMPARISON OF CLINICAL FEATURES AND STRENGTH OF PRECIPITINS

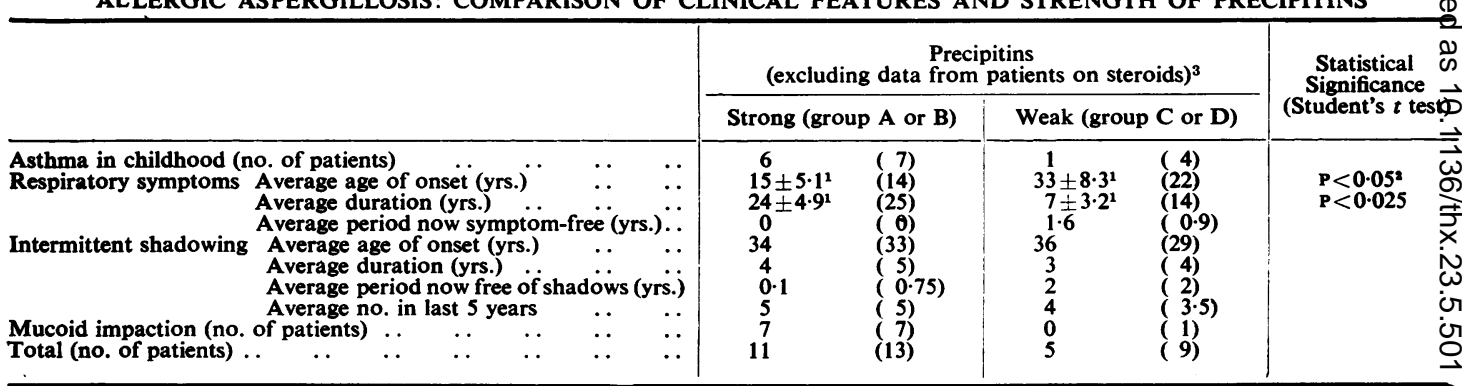

${ }^{1}$ Standard error of means

One tailed test

3 Data from total patients in brackets.

loma. The strongest precipitins recorded were in fact those in cases 2 and 12 , who both experienced current episodes of pulmonary eosinophilia : their sera reacted with all of six antigenic extracts tried, producing a maximum of seven

precipitation lines. Indirect evidence that the occurrence of a new shadow was associated with an immunological reaction was provided b another patient (case 8) with strong precipitin $\bar{s}$, in whom the shadow and increased eosinophiltes

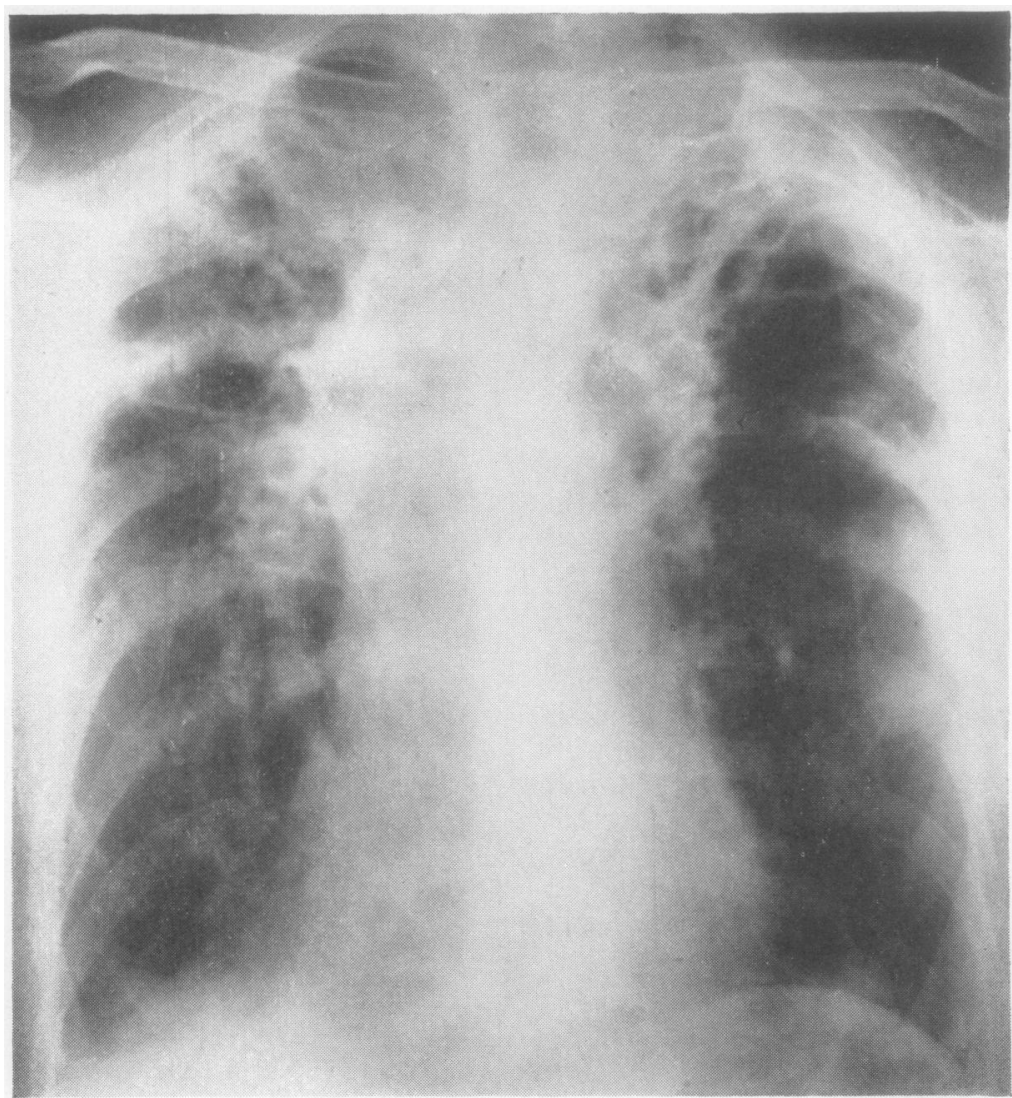

FIG. 5. Case 31. Chest radiograph showing bilateral upper lobe fibrosis. 
coincided with the spontaneous recurrence of a wheal at the site of the intradermal test performed three weeks earlier.

SPUTUM All patients with allergic aspergillosis except case 22 were shown to have abundant $A$. fumigatus in the sputum during the period of this study, although this coincided with a pulmonary shadow in only 15 patients. The fungus was found in every case after examination of no more than three random specimens, in which sputum plugs were not noted. Case 22 with previously positive sputum had been symptom-free in recent years, and no sputum was available.

EOSINOPHILIA The blood eosinophil count, where it had been measured while the patient was not on steroid therapy, was above 500 per cu. $\mathrm{mm}$. during all episodes of pulmonary shadowing, and above 1,000 per cu. $\mathrm{mm}$. at some time in all cases and during all except three observed episodes of pulmonary shadowing. It was also raised in most cases during the intervals between episodes. A count of more than 4,000 per cu. $\mathrm{mm}$. was recorded in two cases (cases 6 and 16), above 3,000 per $\mathrm{cu} . \mathrm{mm}$. in one other (case 15), and above 2,000 per cu. $\mathrm{mm}$. in five others (cases 3, 7, 12, $14,21)$.

DIFFERENTIAL DIAGNosis The pulmonary shadows had at some stage of the illness been attributed to tuberculosis in five patients, to bacterial pneumonia in two, and to carcinoma of the bronchus in two. Two siblings (cases 5 and 6) had missed over a year of school because the lung shadows of aspergillosis had been interpreted as tuberculous.

\section{DISCUSSION}

Positive skin tests to $A$. fumigatus antigens are present in about a quarter of all patients attending hospital in Britain with asthma (Pepys et al., 1959 ; Henderson et al., 1968), and it is possible that specific bronchial allergy to $A$. fumigatus is responsible for symptoms in many of these (Pepys, 1966a). About a quarter of them develop the full syndrome of allergic aspergillosis with pulmonary eosinophilia (Henderson et al., 1968). Its diagnosis is here regarded as established only when all of the five defined criteria were fulfilled. These diagnostic features are intermittent and moreover may be characteristic only of one phase of the natural history of the condition. Ten additional patients with 'probable allergic aspergillosis', all with evidence of fungal infection and hypersensitivity, were therefore included in this series in an attempt to broaden the time scale of the study.

EPIDEMIOLOGY No epidemiological data about the geographical distribution of atmospheric concentrations of $\boldsymbol{A}$. fumigatus spores or of aspergillosis are available. However, it may be noted that more than three times as many cases of allergic aspergillosis were seen in Exeter as during a longer period in Bristol, whether the total number of cases or only new cases are considered; although these studies were not comparable, a real difference in prevalence might exist. In two similar surveys of 107 patients with chronic chest disease in Bristol and 52 patients in the more industrial city of Sheffield, slightly higher proportions of patients with established aspergillosis of all types and of patients with precipitins were found in Bristol, but these differences were not statistically significant (Henderson, English, and Vecht, unpublished data).

The aetiological importance of an environment. rich in $A$. fumigatus spores has repeatedly been adduced in individual cases of invasive and allergic aspergillosis and is again apparent in this series (Coe, 1945 ; Hinson et al., 1952 ; Robinson and McPherson, 1962 ; Strelling, Rhaney, Simmons, and Thomson, 1966). Aspergillosis is probably commoner in certain agricultural regions, where exposure to higher atmospheric spore concentrations may occur, but further epidemiological studies are needed to confirm this impression.

EARLY AND LATE ONSET asthma Patients with allergic aspergillosis with early and late onset asthma were compared. While it is difficult to date the onset of allergic aspergillosis, it is apparent that shadows were first demonstrated at an earlier age in patients with asthma since childhood. This suggests that these patients are more susceptible to the disease. Acquired allergy to $A$. fumigatus is probably but one of many factors in the aetiology of their respiratory symptoms. In contrast, the short average interval of less than a year between the onset of symptoms and shadows in most patients with late onset asthma, when compared with an average interval of over 20 years in the former group, suggests that specific fungal allergy plays a more dominant role in this group. Evidence of a large infecting dose, such as an environment rich in spores, or previous lung disease where localized fungal growth might develop, was found more frequently in those in 
whom asthma developed in adult life; most of these also showed features of underlying atopic diathesis. The data imply that the disease results from a quantitative interaction between atopic diathesis and contact with the fungal antigens.

LUNG SHADOWS The radiographic lesions reviewed in this series consisted of episodic segmental shadowing with deflation. This accords with the original description of lobar or segmental collapse and consolidation in different parts of the lung (Hinson et al., 1952 ; Golberg, 1962), although total fung collapse has also been reported (Ellis, 1965). The lesions occurred significantly more frequently in the upper lobes; their tendency to recur in the same segment suggests that previous bronchial damage predisposes locally to further episodes.

BRONCHIAL DILATATION Saccular bronchiectasis was demonstrated in the segmental or smaller bronchi of an affected segment in six of the nine cases in whom bronchograms had at some time been performed. The appearances were similar to those described by Scadding (1967), who pointed out that a normal bronchiolar pattern is usually present distal to the lesions, in contradistinction to those found after tuberculosis or bacterial pneumonia, and who has also adduced evidence that they follow rather than precede the allergic episodes.

Opaque dilated bronchi, radiating from the hilum and characteristic of mucoid impaction of the bronchi as described by Shaw (1951) and by Harvey, Blacket, and Read (1957), were seen in over a third of the present cases. They were found in areas of previous peripheral shadowing associated with distal saccular bronchiectasis; locally impaired bronchial drainage from prior lung damage may therefore have contributed to their formation.

The distribution of these lesions was similar to that of the lung shadows. In previous reviews of mucoid impaction (Shaw, 1951 ; Harvey et al., 1957) and of pulmonary eosinophilia and asthma (Crofton, Livingstone, Oswald, and Roberts, 1952 ; Young, 1955), the opacities were also found to occur most commonly in the upper lobes; earlier reports of these conditions may well have included unrecognized cases of allergic aspergillosis.

SECONDARY INFECTION Lung shadows may occur without fever or change of symptoms. However, secondary bacterial infection probably accounts in some patients for the fever which is often흠 associated and may respond to antibiotics, for $\frac{\bar{c}}{7}$ the pleurisy which sometimes occurs, and for the $\stackrel{\mathbb{\Phi}}{\propto}$ sudden release of pus and resolution of the shadow following expectoration of a plug that

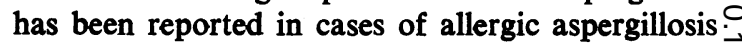
and of mucoid impaction (Plummer, $1958 ; \vec{\omega}$ Harvey et al., 1957). Cystic areas were noted in the affected segments in some of the present $\vec{x}$ cases ; Shaw (1951) has described abscess cavities distal to mucoid impaction.

HAEMOPTYSIS Haemoptysis, a characteristic $\stackrel{\circ}{\rightarrow}$ symptom of aspergillomas, occurred in half the응 present series but was always scanty; it may have been due to infected bronchiectasis or specifically $\mathcal{D}^{\infty}$ to infection by $A$. fumigatus.

COURSE OF DISEASE Plummer (1958) noted that the manifestations of the disease gradually died out after a few years in most of his cases despite $\vec{\odot}$ persistently positive sputum. All except one of $\infty$ our definite cases still had positive sputum, and only two had become free of all symptoms. Fours of the older patients with established allergic aspergillosis had some contraction of the upper lobes with fixed airways obstruction, as had five $\underset{\propto}{\mathbb{\Phi}}$ similar patients with probable allergic aspergillosis $\Rightarrow$ who, it is suggested, might have had unobserved 3 episodes of pulmonary eosinophilia earlier in the course of the disease. Some of the patients witho upper lobe contraction had been on steroids and had no episodes of pulmonary eosinophilia forō over five years, but upper lobe contraction $\stackrel{\otimes}{x}^{0}$ occurred equally in patients not on steroids. Itso presence did not preclude further episodes of lung. shadowing. It probably represents a late stage ofo the condition, although proof of this requires $₹$ more prolonged observation of known cases. It? is of interest that Harvey et al. (1957) observed apical fibrosis in a number of asthmatic patientso following mucoid impaction.

PRECIPITINS AND PATHOGENESIS The nature of 0 the lung shadows and the significance of precipi- - w tins in allergic aspergillosis remain uncertain. ItO has been reported that all patients with episodico pulmonary eosinophilia can be shown, if the testo is carried out with concentrated serum, to have? precipitins as well as reagins, and that a precipitin- $-\frac{0}{T}$ mediated Arthus-type skin reaction can often be produced. This has led to the suggestion that an analogous Arthus-type reaction underlies the $\stackrel{\mathbb{Q}}{\varrho}$ development of the bronchial dilatation or lung shadows (Pepys, 1966a, b). 
A bronchial reaction may, however, be mediated by reagins alone. Allergic aspergillosis differs from other examples of allergy to inhaled antigens in that the antigenic source can grow in the bronchial lumen. Locally, high concentrations of antigen may then provoke a florid reaction which allows continued growth of the trapped fungus; the resultant bronchial plugging will then lead to the development of distal areas of collapse ; similar, more peripheral lesions are found in many patients dying with severe asthma (Dunnill, 1960). The presence of precipitins in nonallergic patients probably reflects the amount and duration of contact with the antigen (Henderson et al., 1968). It has been said that the precipitins in allergic aspergillosis are usually weak, so providing conditions of antigen excess appropriate to the most vigorous reactions (Pepys, 1966b). The present data do not show an inverse relationship between the strength of precipitins and the frequency or severity of episodes of pulmonary eosinophilia. Allergic episodes were observed as commonly in those with strong precipitins as in those with weak precipitins. The strength of precipitins appeared rather to be directly related to the amount of antigen exposure. The occurrence of precipitins only in those asthmatic patients with positive skin tests who also experience pulmonary shadows would be a measure of the greater antigen exposure to be expected in these patients, both to initiate a reaction sufficiently florid to cause bronchial plugging and as a result of the vicious circle so set up.

The radiological features of the peripheral lung shadows and the few available pathological studies (Hinson et al., 1952 ; Belcher and Plummer, 1960) do not exclude the possibility that most, if not all, of these are due simply to areas of nonspecific collapse. The bronchiectasis that develops is peculiarly characteristic; that a bronchial Arthus-type reaction contributes to its pathogenesis remains an intriguing possibility, although bronchial dilatation may follow prolonged occlusion from many causes, and peripheral saccular bronchiectasis related to bronchial plugging is found in other cases of severe asthma (Leopold, 1961).

The predominantly upper lobe distribution of tuberculosis (Royal College of Physicians, 1948) has been considered to be related to poor perfusion of the upper lobes (Boyd, 1965); relative underventilation is probably a more relevant factor in determining the similar distribution of aspergillomas (Villar, Pimentel, and Costa, 1962 ; Golberg, 1962 ; Campbell and Clayton, 1964) and of the lesions in allergic aspergillosis, where the fungus is growing within a lung cavity or bronchial lumen. Bronchiectasis of the upper lobes was found in only $1 \%$ of patients with known bronchiectasis by Perry and King (1940) ; although this may underestimate the real prevalence, since gravitational drainage tends to prevent the chronic bacterial infection which usually leads to its recognition, it is generally considered to be uncommon. In contrast, it is typical of allergic aspergillosis, where the secretions are viscid and not easily drained.

It is likely that host response to the fungal antigens becomes modified with the course of time and treatment so that episodes of asthma and pulmonary eosinophilia no longer occur. If there is little permanent lung damage, the nidus of fungal infection will be expectorated as the asthma is relieved (case 24). If permanent lung damage has resulted from earlier episodes, fungal colonization of the diseased air spaces will probably persist. It may then remain occult, or it may cause chronic lung contraction, attributable to persistent bronchial occlusion or to damage caused by hypersensitivity reactions in the lung parenchyma or by fungal endotoxins. The fungus may become invasive if host resistance is lowered (case 31), or it may form an aspergilloma (case 32). Aspergillomas are thought usually to arise in pre-existing lung cavities or necrotic lesions. Small fungal masses have, however, been demonstrated radiographically in bronchiectatic sacs (Vantrappen, Simons, Woestijne, and Gyselen, 1959), enlargement of aspergillomas and their cavities is well documented (Golberg, 1962; Macartney, 1964), and it is probable that they result from localized fungal growth in any poorly drained lung space (Pesle and Monod, 1954; Segretain, 1962 ; Villar et al., 1962).

I should like to express my gratitude to all who have helped in the preparation of this paper: to Mary P. English for the mycological studies and for her continued encouragement; to Dr. Peter Watts for his assistance in the review of the radiographs; to Dr. J. E. G. Pearson and all the other physicians, surgeons, and general practitioners who have encouraged me to study patients under their care, including Dr. G. E. Adkins, Dr. D. R. Coles, Dr. M. Cranna, Dr. A. J. Daly, Dr. B. Finzel, Dr. J. A. S. Forman, Dr. P. W. Foster, Mr. J. L. Griffiths, Dr. G. H. Hall, Dr. B. R. Hillis, Dr. F. J. D. Knights, Dr. D. Mattingly, and Dr. D. B. Shaw. I am most grateful to Professor J. Pepys and Dr. J. Longbottom for their helpful criticism of the manuscript. 


\section{REFERENCES}

Belcher, J. R., and Plummer, N. S. (1960). Surgery in bronchopulmonary aspergillosis. Brit. J. Dis. Chest, 54, 335.

Boyd, W. (1965). Pathology for the Physician. 7th ed., p. 307. Kimpton, London.

Campbell, M. J., and Clayton, Y. M. (1964). Bronchopulmonary aspergillosis. A correlation of the clinical and laboratory findings in 272 patients investigated for bronchopulmonary aspergillosis. Amer. Rev. resp. Dis., 89, 186.

Chakravarty, S. C. (1964). Incidence and significance of fungi in sputum in bronchopulmonary disease. Acta tuberc. scand., 45, 295 .

Citron, K., and Fepys, J. (1958). In Fungous Diseases and Their Treatment, ed. Riddell, R. W., and Stewart, G. T. p. 134 Butterworth, London.

Coe, G. C. (1945). Primary bronchopulmonary aspergillosis, an occupational disease. Ann. intern. Med., 23, 423.

Conant, N. F., Smith, D. T., Baker, R. D., Callaway, J. L., and Martin, D. S. (1944). Manual of Clinical Mycology. 1st ed. Saunders, Philadelphia and London.

Crofton, J. W., Livingstone, J. L., Oswald, N. C., and Roberts, A. T. M. (1952). Pulmonary eosinophilia. Thorax, 7, 1.

Dunnill, M. S. (1960). The pathology of asthma, with special reference to changes in the bronchial mucosa. J. clin. Path., 13, 27.

Ellis, R. H. (1965). Total collapse of the lung in aspergillosis. Thorax, 20,118

English, M. P., and Henderson, A. H. (1967). Thé significance and interpretation of labcratory tests in pulmonary aspergillosis. J. clin. Path., 20, 832.

Golberg, B. (1962). Radiological appearances in pulmonary aspergillosis. Clin. Radiol., 13, 106.

Harvey, C., Blacket, R. B., and Read, J. (1957). Mucoid impaction of the bronchi. Aust. Ann. Med., 6, 16

Henderson, A. H., English, M. P., and Vecht, R. J. (1968). Pulmonary aspergillosis: a survey of its occurrence in patients with chronic lung disease and a discussion of the significance of diagnostic tests. Thorax, 23, 513.

Hinson, K. F. W. (1958). In Fungous Diseases and their Treatment, ed. Riddell, R. W., and Stewart, G. T. p. 123. Butterworth London.

- Moon, A. J., and Plummer, N. S. (1952). Broncho-pulmonary aspergillosis; a review and a report of eight new cases. Thorax, 7 . 317.

Leeuwen, W. Storm van, Bien, Z., Kremer, W., and Varekamp, H. (1925). Ueber die Bedeutung kleinsporiger Aspergillus-Arten
(Typus Aspergillus fumigatus) fûr die Aetiologie des Asthm: bronchiale. Z. Immun.-Forsch., 44, 1.

Leopold, J. G. (1961). Allergic pneumonia in chronic asthmatics Thorax, 16, 400 .

Longbottom, J. L., and Pepys, J. (1964). Pulmonary aspergillosis diagnostic and immunological significance of antigens ands C-substance in Aspergillus fumigatus. J. Path. Bact., 88, 141.

Macartney, J. N. (1964). Pulmonary aspergillosis: a review and $\vec{P}$ description of three new cases. Thorax, 19, 287.

Pepys, J. (1966a) Pulmonary hypersensitivity disease due to inhale $\vec{\omega}$ organic antigens Postgrad. med. J., 42, 698.

- (1966b). Pulmonary hypersensitivity disease due to inhaled organic antigens. Ann. intern. Med., 64, 943.

—— Riddell, R. W., Citron, K. M., Clayton, Y. M., and Short, E. I (1959). Clinical and immunologic significance of Aspergillu.w fumigatus in the sputum. Amer. Rev. resp. Dis., 80, 167.

Perry, K. M. A., and King, D. S. (1940). Bronchiectasis; a study of prognosis based on a follow-up of 400 patients. Amer. RevO Tuberc., 41, 531 . Pesle, G. D., and Monod, O. (1954). Bronchiectasis due to asper윽
gilloma. Dis. Chest, 25, 172.

Plummer, N. S. (1958). In Fungous Diseases and Their Treatment, ed. Riddell, R. W., and Stewart, G. T. p. 234. Butterworth is London.

Robinson, C. L. N., and McPherson, A. R. (1962). Bronchopulmonar aspergilloma. Canad. J. Surg., 5, 411.

Royal College of Physicians (1948). Tuberculosis in Young Adults Report on the Prophit Tuberculosis Survey 1935-1944 (1956) Lewis, London.

Scadding, J. G. (1967). The bronchi in allergic aspergillosis. Scand. J resp. Dis., 48, 372.

Segretain, G. (1962). Pulmonary aspergillosis. Lab. Invest., 11, 1046ळ

Shaw, R. R. (1951). Mucoid impaction of the bronchi. J. thorac Surg., 22, 149 .

Strelling, M. K., Rhaney, K., Simmons, D. A. R., and Thomson, Js (1966). Fatal acute pulmonary aspergillosis in two children of one family. Arch. Dis. Childh., 41, 34.

Vantrappen, G., Simons, C., Woestijne, K. P. van de, and Gyselen, A (1959). Intracavitary and intrabronchial fungus masses. $D i s \stackrel{2}{\mathbb{D}}$
Chest, 35, 528.

Villar, T. G., Pimentel, J. C., and Freitas e Costa, M. (1962). The tumour-like forms of aspergillosis of the lung (pulmonary aspergilloma). A report of five new cases and a review of the Portuguese gilloma). A report of five
literature. Thorax, $17,22$.

Young, R. D. (1955). Prolonged pulmonary eosinophilia. Brit. $J$ Tuberc., 49. 129 